\title{
A seed midge pest of big bluestem
}

\author{
M.R. CARTER, G.R MANGLITZ, M.D. RETHWISCH, AND K.P. VOGEL
}

\section{Abstract}

A Cecidomyild midge reared from the panicles of big bluestem (Andropogon gerardil Vitman (var. gerardil) at Mead, Neb., was identified as Contarinia wattsi Gagné. This midge was previously known only from panicles of hittle bluestem (Schizachyrium scopariwm (Michx.) Nash) in New Mexico. In Nebraka, C. wattsi appears to have a minimum of 3 generations per season. Larvae of the earlier generations leave the florets after completing development, making it difincult to associate foret damage with the midge. Larvae of the last generation of a season remain in diapause, in the loret, throughout the winter. Evidence obtained in this study in 1985 indicates that, at harvest time, 7 and $15 \%$ of the florets in the 2 fields studied contained diapausing midges. However, when an estimnte of seed loss by the earlier generations (as indicated by empty forets and small seed) was considered, the total loss was probably closer to $40 \%$. An unidentified species of thrips (Thysanoptera: Thripidae) also was found in bis bluestem florets during this study. However, evidence suggests that thrips do not damage big bluestem seed as seriously as the midge.

\section{Key Words: seed production, Contarinia wattst}

Commercial seed production of big bluestem (Andropogon gerardii Vitman var. gerardii) in cultivated seed production fields began in the 1930's in eastern Kansas (Cornelius 1950). In the early years of commercial seed production, seed yields averaged from 80 to $170 \mathrm{~kg} /$ ha pure live seed (PLS) although seed yields as high as $334 \mathrm{~kg} / \mathrm{ha}$ were reported (Cornelius 1950, Schumacher 1962). In recent years seed growers have regularly produced seed yields as high as $560 \mathrm{~kg} / \mathrm{ha}$ by using improved production practices (Vogel and Gabrielsen 1986, Nebraska Crop Improvement Association 1986, personal communication), but occasionally seed yields have plummeted to levels less than the early seed yields for no apparent reason (personal communications from Nebraska seed growers). Cornelius (1950) reported from Kansas that orange colored larvae of an insect were found occupying the caryopsis space in $13 \%$ of the florets of big bluestem examined in 1945. He was unable to identify the insect. Vogel and Gabrielsen (1986) suggested that insects may be an undocumented problem in seed production fields of native prairie grasses.

The level of fertility and abortion of big bluestem florets in the absence of insects is unknown. However, in fields and nurseries in Kansas comparable to those in this study, Law and Anderson (1940) reported average seed set percentages of 18 to $46 \%$ and Cornelius (1950) found an average seed set of $41 \%$. In these studies, seed set was the number of florets containing a caryopsis divided by the total number of florets examined. On individual plants, Law and Anderson (1940) reported seed set percentages ranging from 0 to $84 \%$. These reports did not indicate if pedicellate spikelets were included in the counts.

Very few midges (Diptera: Cecidomyiidae) have been recognized as pests of grass seed production. One reported midge is Contarinia

\footnotetext{
Authors are former graduate research assistant, Dept. of Entomology, Univ. of Nebraska; research entomologist, USDA-ARS; former graduate research assistant, Dept. of Entomology, Univ. of Nebraska; and supervisory research geneticist, USDAARS; Univ. of Nebraska, Lincoln 68583.

Contribution No. 8325 of the Nebraska Agricultural Research Division, Univ. of Nebraska, Lincoln, and the Agricultural Research Service, U.S. Department of Agriculture.

The authors wish to thank Dr. Raymond Gagne, USDA-ARS, c/o U.S. National Museum, Washington, D.C., for identifying many midge specimens during the early stages of this study. Thanks also due to Cindy Vinovskis for her patience in dissecting big bluestem florets.

Manuscript accepted 24 November 1987.
}

(=Stenodiplosis) bromicola (Marikovsky and Agafonova) which was reported to reduce seed production of smooth bromegrass (Agafonova 1962, Neiman and Manglitz 1972). This bromegrass seed midge apparently was distributed widely in both the USSR and US before it was discovered and its damage realized. Another midge, Contarinia wattsi Gagné, was described by Gagné (1966) from specimens collected from little bluestem (Schizachyrium scoparium (Michx.) Nash) in New Mexico. C. wattsi destroyed $20 \%$ of the little bluestem seed (Watts and Bellotti 1967). The objectives of this study were to determine if insects were damaging florets or developing seeds of big bluestem and if so, to determine the effect of this damage on seed yield.

\section{Materials and Methods}

Insect populations were sampled during 1983 and 1985 in a foundation seed field of 'Pawnee' big bluestem (Field 1) at the University of Nebraska's Agricultural Research and Development Center at Mead, Neb. Sampling in 1983 began in late-July and continued on a weekly basis until 21 September. In 1985, the same field was sampled twice weekly from mid-July through 21 September. A polycross nursery of clones selected from 'Kaw' big bluestem (Field 2) was also sampled on 21 September 1985. The 2 fields were about $2 \mathrm{~km}$ apart. The midge population was sampled by randomly collecting 25 to 35 panicle-bearing culms from the fields. The culms were taken to the laboratory and placed in water-filled flasks, which were placed in dark insect-rearing cages. Insects emerging from florets were collected in glass vials inserted in the side of the cages. Culms and racemes remained in the rearing cages for 4 weeks, then they were transferred to paper bags and held at $2^{\circ} \mathrm{C}$ for later dissection.

In 1985 numbers of insects and seed development stage were determined by dissecting approximately $25 \%$ of the florets collected on each date. Big bluestem has both sessile and pedicellate spikelets. According to Hitchcock (1951) the floret of the sessile spikelet is fertile but the pedicellate spikelet is sterile. However, in breeding nurseries and in seed production fields, the pedicellate spikelete can be fertile (Boe et al. 1983). Boe et al. (1983) reported that in eastern South Dakota nurseries as many as $86 \%$ of the big bluestem plants had fertile pedicellate spikelets. In this study both sessile and pedicellate spikelets were dissected since the plants were grown in nursery and field conditions conducive to seed set in the pedicellate spikelets. Dissected florets were visually classified according to size, stage of development, and the presence or absence of insects using the following categories.

1. Normal seed-fully developed, large and medium sized seed.

2. Small seed-developed but very small.

3. No seed-floret ovaries were destroyed by the midge or failed to develop for other reasons.

4. Midge-orange diapausing pupae (or puparium) was found in the floret.

\section{Results and Discussion}

The insect which emerged most frequently from panicles of big bluestem in 1983 was Contarinia wattsi Gagné. Its association with big bluestem and its occurrence in Nebraska are both new records;thus, determining the seasonal occurrence of and damage potential for $C$. wattsi became the primary focus for the remainder of the observations. 
The numbers of $C$. wattsi that emerged from the panicles in the rearing cages at weekly intervals indicate that at least 3 generations per year occurred in Nebraska in 1985. Generations were indicated by emergence peaks that occurred about every 13 to 16 days (Fig. 1). In 1983, collection of panicles was initiated too late in August to record the first generation. However, what appeared to be second and third generations were observed. Emerging midges left no evidence of their former presence in the floret. This lack of evidence makes damage assessment very difficult.

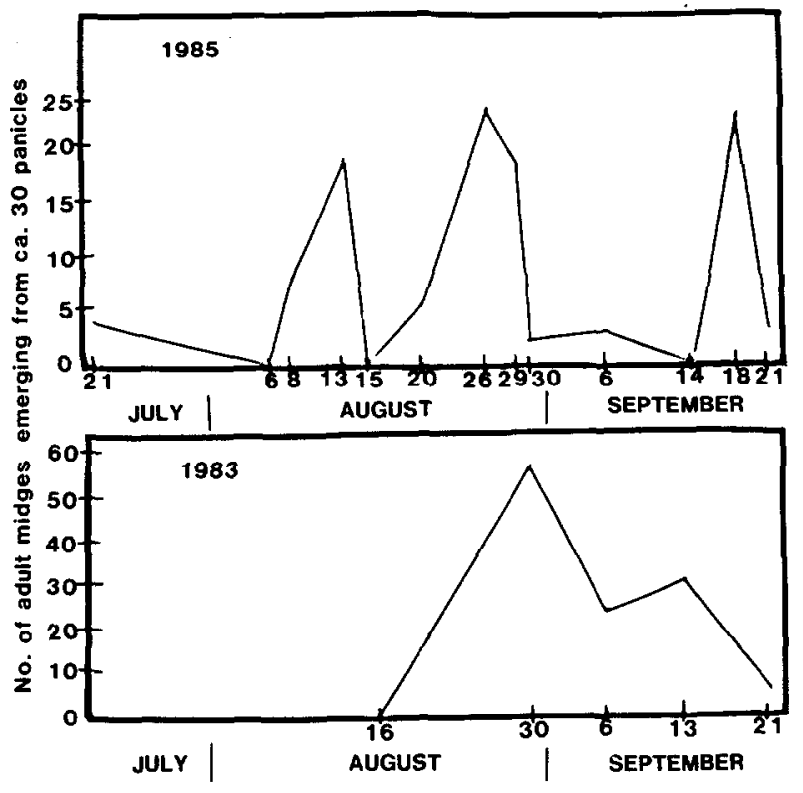

Fig. 1. The emergence of adult midges from field collected panicles of big bluestem during the summers of 1983 and 1985 at Mead, Neb.

Dissection of florets collected early in the season revealed the presence of immature larvae, which would be expected to complete development and emerge as adults later in the season. As the season progressed, the percentage of the dissected florets that contained diapausing midge larvae increased (Table 1). Midge

Table 1. Seasonal progression of diapausing midges in 'Pawnee' big bluestem field during mid- to late-summer, Mead, Nebraska, 1985.

\begin{tabular}{cccc}
\hline & \multicolumn{2}{c}{ Diapausing midges } \\
\cline { 2 - 4 } Collection date & $\begin{array}{c}\text { Mean infested } \\
\text { florets }(\%)\end{array}$ & $\begin{array}{c}95 \% \text { confidence } \\
\text { interval (range) }\end{array}$ \\
\hline August & 7 & 0 & -1.4 \\
& 13 & 0.7 & $0.35-2.75$ \\
21 & 1.8 & $0.08-2.66$ \\
29 & 4.9 & $0.39-3.69$ \\
September & 6 & 14.9 & $1.83-7.38$ \\
& 21 & $6.48-27.27$ \\
& $X^{2}=213.352\left(X^{2}{ }_{0.06} \text { 5 d.f. }=11.070\right)^{1}$ & \\
\hline
\end{tabular}

'Rejects hypothesis that \% midges in florets does not change as season progresses. Analysis used is according to Zar (1984).

larvae were found in 18 and $7 \%$, respectively, in the Pawnee and Kaw florets sampled on 21 September (Table 2). In addition, an unidentified species of thrips (Thysanoptera: Thripidae) was found in the Pawnee florets; but the number of florets containing thrips was relatively low (1.8 on 29 August) until September (17.8 on 21 September), when the caryopses were nearly mature. Therefore, the influence of these thrips on seed production is probably not significant. More observations are needed to fully assess the damage potential of the thrips to big bluestem seed. On the 21 September sampling date $77 \%$ of the Pawnee florets and $59 \%$ of the Kaw florets had either midges, no seed, or small seed (Table 2). The florets with no seed or small seed may have been damaged by earlier generations of midges. Assuming that in the absence of these insects and under optimal conditions all sessile and pedicellate spikelets set seed, then $15 \%$ of the Pawnee florets contained midges rather than caryopses. Many of the florets which were empty (47\%) or contained small seeds (12\%) probably were damaged by earlier generations of midges (Table 2). Since many of the pedicellate spikelets do not set seed under field conditions, we conservatively estimate that $40 \%$ of the potential seed crop in the Pawnee field was destroyed by midges. The damage was less in the Kaw field but it was still substantial since only $41 \%$ of the florets had "normal" seed.

Table 2. Seed development and presence of insects in 2 seed fields of big bluestem in eastern Nebraska. Samples taken 21 September 1985.

\begin{tabular}{lccccc}
\hline \hline \multirow{2}{*}{ Floret } & \multicolumn{2}{c}{ Field 1, 'Pawnee' } & & \multicolumn{2}{c}{ Field 2, 'Kaw' } \\
\cline { 2 - 3 } \cline { 5 - 6 } categories & No. & $\%$ & & No. & $\%$ \\
\hline Normal seed & 110 & 23 & & 377 & 41 \\
Small seed & 56 & 12 & & 318 & 34 \\
No seed & 226 & 47 & & 169 & 18 \\
Midges & 87 & 18 & & 63 & 7 \\
$\quad$ Total & 479 & 100 & & 927 & 100 \\
\hline
\end{tabular}

In summary, this study represents the first report of the seed midge, Contarinia wattsi, on big bluestem and only the second time it has been reported in North America. Judging from the few but widespread locations where it has been found, including South Dakota (Arvid Boe, 1986, personal communication), the midge probably is widely distributed and may be found in many areas where native stands of big bluestem remain. Additional research will be needed to further quantify the damage of this bluestem seed midge and the unidentified thrips on seed yields of big bluestem and to develop control practices.

\section{Literature Cited}

Agafonova, Z. Ya. 1962. Development of the midge Stenodiplosis bromicola Mar. et Ag. (Diptera: Itonididae), in relation to peculiarities of brome biology (Bromus inermis Leyess. and riparius Rehm.). Rev. Entomol. 41:11-21.

Boe, A.A., J.G. Ross, and R. Wynis. 1983. Pedicellate spikelete fertility in big bluestem from eastern South Dakota. J. Range Manage. 36:131-132.

Cornelius, D.R. 1950. Seed production of native grasses under cultivation in eastern Kansas. Ecol. Monogr. 20:3-29.

Gagné, R.J. 1966. The Neartic species of Contarinia which infest grasses (Diptera: Cecidomyiidae). Proc. Entomol. Soc. Wash. 68:318-321.

Hitchcock, A.S. 1951. Manual of the grasses of the United States. USDA Misc. Pub. No. 200. 2nd ed. revised by Agnes Chase. U.S. Gov't. Printing Office, Washington, D.C.

Law, A.G., and K.L. Anderson. 1940. The effect of selection and inbreeding on the growth of big bluestem (Andropogon furcatus Muhl.). J. Amer. Soc. Agron. 32:931-943.

Neiman, E.L., and G.R. Manglitz. 1972. The biology and ecology of the bromegrass seed midge in Nebraska. Nebraska. Agr. Exp. Sta. Res. Bull. 252.

Schumacher, C.M. 1962. Grass seed production in Nebraska and South Dakota. USDA-SCS Technical Guide-Section IV-G, USDA-SCS, Lincoln, Neb.

Vogel, K.P., and B.C. Gabrielsen. 1986. Breeding to improve native warmseason grasses. pp. 27-34. In: Warm-season grasses. Balancing forage programs in the Northeast and Southern Corn Belt. Soil Conserv. Soc. of Amer., Ankeny, Iowa.

Watts, J.G., and A.C. Bellotti. 1967. Some new and little known insects of economic importance on range grasses. J. Econ. Entomol, 60:961-963.

Zar, J. 1984. Biostatistical analysis. 2nd Ed., 718 pp. Prentice-Hall, Inc., Englewood Cliffs, N.J. 